\title{
Redundant or Secondary Publication
}

\author{
Tae Gon Kim
}

Deputy Editor, Archives of Plastic Surgery

Department of Plastic and Reconstructive Surgery, Yeungnam University College of Medicine, Daegu, Korea

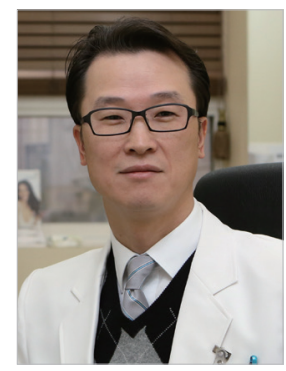

Redundant or duplicate publication is the republishing of a previously published paper in another journal. Such activity violates publishing ethics. This is because originality is a fundamental factor in a scientific paper.

Up until 2006, redundant publication had not been uncommon in the medical community, and it was a usual practice among many South Korean authors to republish papers in prominent international journals in English after having previously published them in Korean language journals. In 2006, the Korean Academy of Medical Science (KAMS) and the Korean Association of Medical Journal Editors (KAMJE) brought attention to the problem of redundant publication and announced their official position discouraging this practice, based on the 'Uniform Requirements for Manuscripts submitted to Biomedical Journals' of the International Committee of Medical Journal Editors (ICMJE).

After this, KAMS and KAMJE worked to eliminate redundant publication through ongoing promotion and education, and in March 2009 they released the 'Good Publication Practice Guidelines for Medical Journals' [1]. So, practically speaking, redundant publication up until 2009 was permitted as a convention in the medical field.

The problem of redundant publication is just as prevalent in the field of plastic surgery as any other specialty. It was not uncommon for authors to publish their papers in the Journal of the Korean Society of Plastic and Reconstructive Surgeons (JKPRS), which was being published in the Korean language, and then later resubmit them to a prestigious Science Citation Index journal. There had been no regulations concerning research and publishing ethics in JKPRS, but in the November issue of 2008 (Vol. 35 No. 6), a 'Provision on Research Ethics' was added to the Instructions for Authors in the journal. At that time, however, a lack of promotion as well as lack of awareness among members made it difficult to elicit much change.

The situation did change after the establishment of the Archives of Plastic Surgery (APS) in 2012 to replace JKPRS. The editor-in-chief at the time, Jeong Tae Kim, stated in the editorial of the first issue that APS would be published in English, launching its new identity as an international journal. He emphasized that from that moment onward, the practice of redundant publication, where papers published in domestic (Korean) journals were republished in journals outside South Korea, would have to be eradicated [2]. This was also the first time redundant publication emerged as an issue in print in the plastic surgery field. Therefore, beginning in 2012, in cases where a paper published in South Korea has been republished in an international journal, the journal that published the first version of the paper should request that the latter paper be retracted, in accordance with regular publishing ethics.

With respect to redundant publication occurring prior to 2012, it is open to dispute as to whether it is appropriate to apply publishing ethics regulations in the strictest manner, or to see it as the common practice of that time and tacitly accept that it happened among members of our academic society. Should the redundant publication of a paper be brought to the attention of a journal, action should be taken following the Committee on Publication Ethics (COPE) flowchart (Fig. 1). For further guidance on handling duplicate publications, readers should refer to 
Fig. 1. Flowchart for further guidance on handling duplicate publication by the Committee on Publication Ethics [3]

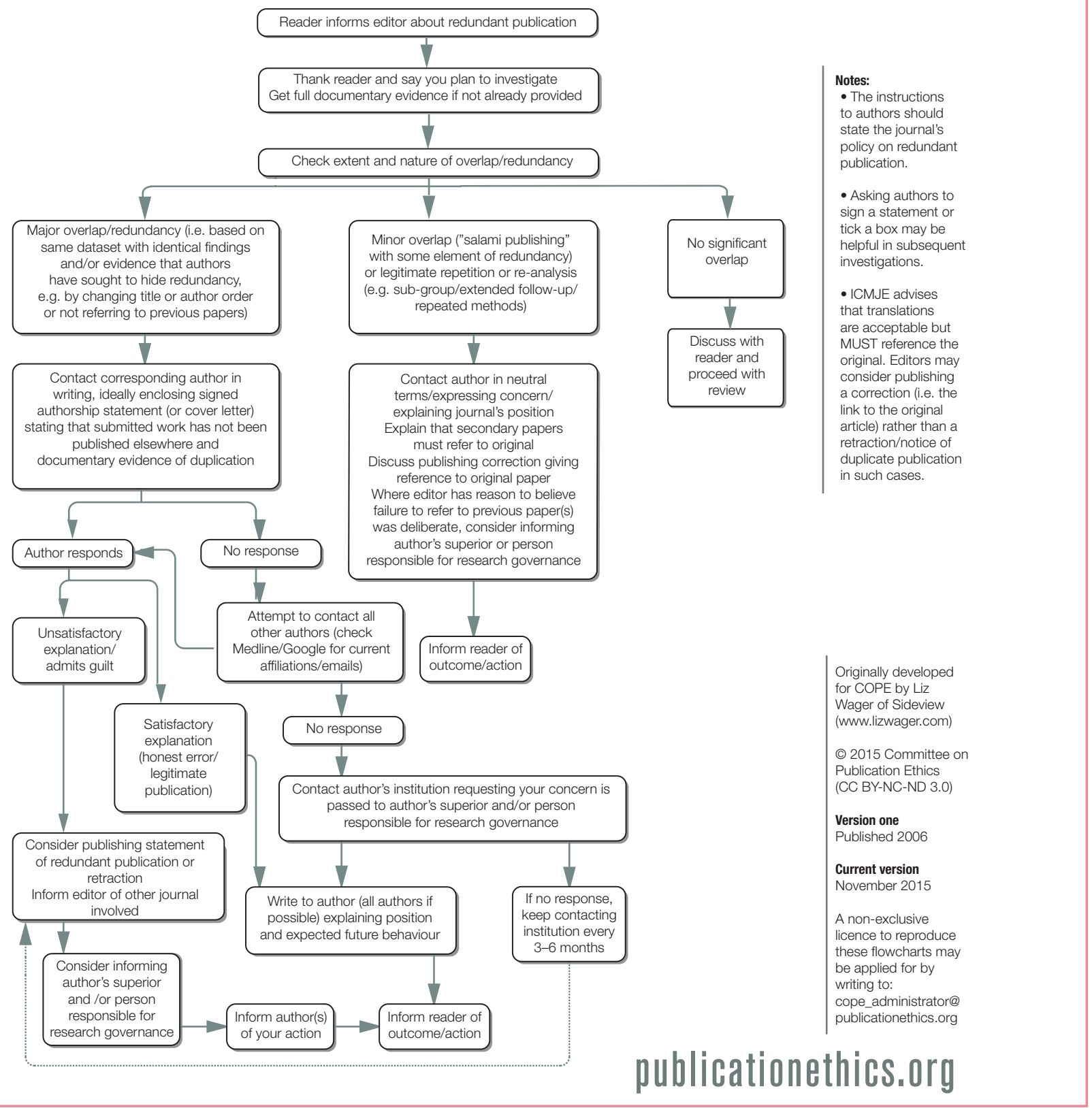

the recommendations of the COPE [3]. This recommendations include publishing statements of redundant publication or retraction.

However, the following excerpt notes that cases of translation may be handled differently from the regular process of dealing with redundant publication. "ICMJE advises that translations are acceptable but MUST reference the original. Editors may consider publishing a correction (i.e., the link to the original article) rather than a retraction/notice of duplicate publication in such cases."

This means that, should a paper initially published in Korean be translated into a foreign language and republished, rather than issuing a retraction, it can be dealt with by issuing a corrigendum and linking to the original paper. This approach takes into consideration a foreign-language speaking readership as one of the conditions for acceptable secondary publication [4]. Of course, it should be an innocent, unintentional mistake and not purposeful. When redundant publication is discovered and becomes an issue, the journal that first published the paper has priority. It would be a normal ex post facto measure for a journal with priority of primary publication to request a journal that has republished a paper to issue a retraction. However, it appears that, within ICMJE as well, an exception is being made in the rules with respect to translated papers. 
It is difficult to know precisely in which direction the recommendations of COPE and ICMJE will change with time. However, at the current point in time, when a case like this occurs among our members, we believe that it is appropriate that the fact of redundant publication be accepted with humility and that both parties - the author and the second journal-cooperate with the editorial committee in order to settle the issue amicably.

\section{ORCID}

Tae Gon Kim http://orcid.org/0000-0002-6738-4630

\section{REFERENCES}

1. Korean Association of Medical Journal Editors. Good publication practice guidelines for medical journals, 2nd [Internet]. Seoul: Korean Association of Medical Journal Editors; 2008 [cited 2016 Feb 21]. Available from: http://www.kamje.or.kr/intro.php?body=publishing_ethics.

2. Kim JT. Evolution to a renowned international journal. Arch
Plast Surg 2012;39:1-2.

3. Committee on Publication Ethics. Guidelines on Good Publication Practice [Internet]. London: Committee on Publication Ethics; 2015 [cited 2016 Feb 21]. Available from: http://publicationethics.org/files/redundant\%20publication\%20B.pdf.

4. International Committee of Medical Journal Editor. Overlapping publications [Internet]. International Committee of Medical Journal Editor; 2016 [cited 2016 Feb 21]. Available from: http://www.icmje.org/recommendations/browse/ publishing-and-editorial-issues/overlapping-publications. html.
Correspondence: Tae Gon Kim

Department of Plastic and Reconstructive Surgery, Yeungnam University College of Medicine, 170 Hyeonchung-ro, Nam-gu, Daegu 42415, Korea

Tel: +82-53-620-3480, Fax: +82-53-626-0705, E-mail: kimtg0919@gmail.com

No potential conflict of interest relevant to this article was reported.

Received: 2 Mar 2016• Revised: 3 Mar 2016• Accepted: 3 Mar 2016 pISSN: 2234-6163 • elSSN: 2234-6171

http://dx.doi.org/10.5999/aps.2016.43.2.131 • Arch Plast Surg 2016;43:131-133 